\title{
Airway bacteria of the recipient but not the donor are relevant to post-lung transplant pneumonia
}

\author{
Yusuke Konishi $^{1} \cdot$ Kentaroh Miyoshi $^{1,2}$ (1) Takeshi Kurosaki $^{2} \cdot$ Shinji Otani ${ }^{1} \cdot$ Seiichiro Sugimoto $^{1} \cdot$ Masaomi Yamane $^{1}$. \\ Takahiro Oto ${ }^{2} \cdot$ Shinichi Toyooka ${ }^{1,2}$
}

Received: 8 October 2019 / Accepted: 10 December 2019 / Published online: 17 December 2019

(c) The Japanese Association for Thoracic Surgery 2019

\begin{abstract}
Background Optimal management of early airway infection is essential for the survival of lung transplant (LTx) recipients during the first 12 months after transplantation. This study aimed to explore the main cause of post-lung transplant pneumonia (PLTP) within 30 days after LTx.

Methods Forty LTx patients were retrospectively analyzed. Sputum sampling from donors' and recipients' airways was performed pretransplant and posttransplant daily for the first 30 days after LTx. Organisms in the recipient's and donor's original airways were compared to pathogens responsible for PLTP. Patients with and without PLTP were also compared to identify relevant risk factors.

Results Seventeen (42.5\%) patients developed pneumonia (PLTP group) and 23 had no episode of pneumonia (Non-PLTP group) during the first 30 days. In the PLTP group, median time from LTx to PLTP onset was 6 days. A significantly higher incidence of PLTP was caused by recipient's rather than donor's original airway bacteria ( $62 \%$ vs $13 \%, p<0.01)$. Smoking history of the donor and pretransplant airway bacterial colonization of the recipient were independent risk factors of PLTP which was associated with prolonged posttransplant mechanical ventilation with longer intensive care unit stay and worse survival outcomes.

Conclusions The recipient's original airway microflora rather than the donor's, was highly associated with PLTP. A combination of donor smoking history and recipient airway infection should be avoided, while evidence of donor lung infection is not a contraindication for LTx.
\end{abstract}

Keywords Airway colonization $\cdot$ Posttransplant pneumonia $\cdot$ Lung transplantation

\section{Introduction}

Lung transplantation (LTx) is currently a well-established treatment for various end-stage pulmonary diseases, while donor shortage and narrow organ utilization remain limitations in terms of the growing number of indications and candidates. In clinical practice, only $15-25 \%$ of multi-organ donors are reportedly regarded as having organs suitable for

Kentaroh Miyoshi

kmiyoshi@okayama-u.ac.jp

1 Department of Thoracic Surgery, Okayama University Graduate School of Medicine, Dentistry and Pharmaceutical Science, Okayama University Hospital, 2-5-1, Shikata-cho, kita-ku, Okayama 700-8558, Japan

2 Organ Transplant Center, Okayama University Hospital, 2-5-1, Shikata-cho, kita-ku, Okayama 700-8558, Japan transplantation [1-4]. Generally, the donor's clinical markers listed on the standard donor acceptance criteria are still widely used for evaluation and decision-making processes. Evidence of a donor's airway infection, detected via bronchoscopy, is one of the determinants for discarding lungs [5]. Basically, a cadaveric donor is susceptible to ventilatorassociated pneumonia. Mechanical ventilation lasting longer than $48 \mathrm{~h}$ reportedly correlated with pneumonia, particularly in patients with severe brain injuries like those in cadaveric donors [6, 7]. In fact, airway bacteria were reportedly identified in more than $50-89 \%$ of potential lung donors $[8,9]$. Thus, the possibility of a donor's airway infection is a common reason for rejecting organ offers.

Infection is one of the major complications in the acute posttransplant period and a common cause of death in the first year after LTx $[10,11]$. Also, the development of bronchiolitis obliterans syndrome, the leading cause of long-term 
mortality, is often triggered by graft infection [12]. Accurate pretransplant risk assessment of post-lung transplant pneumonia (PLTP) is essential for sensible donor selection and successful posttransplant management. However, the clinical markers relevant to the development of PLTP have not been well identified. A number of offered lungs were discarded for the reason of evidence or the potentiality of donor respiratory tract infection, while the actual impact of microorganisms in the donor's airway on PLTP remains an open question. The potential causes of PLTP are not only transmission of donor organisms, but also remaining organisms in the recipient's trachea or upper airway, and de novo infection after LTx. The aim of this study is to explore the main causes of PLTP development during the first 30 days after LTx by specifically identifying bacterial species in the airways of donors and recipients and examining relevant clinical markers.

\section{Patients and methods}

\section{Patients and study design}

A total of 40 consecutive deceased LTx performed between September 2007 and March 2014 in Okayama University Hospital were retrospectively analyzed. We reviewed the medical records to ascertain the independent variables determining the clinical characteristics and posttransplant outcomes of donors and recipients. Respiratory samples of the donors and recipients were cultured pre- and posttransplant and existent bacteria were identified at each stage. Recipients who developed pneumonia within the first 30 days after LTx were defined as the post-lung transplant pneumonia (PLTP) group. In the PLTP group, bacteria grown at the onset of PLTP were compared to the pretransplant bacterial culture of donors and recipients to determine the origin of the responsible bacteria. In addition, risk factors for PLTP development were identified by comparing clinical characteristics between the PLTP and non-PLTP groups (those with no episode of PLTP during the first 30 days after LTx). Patients' consent for the use of clinical information was obtained in advance. Clinical data recorded until March 2014 were reviewed following approval of the institutional review board of Okayama University Hospital (approval \#: 1804-043).

\section{Recipient and donor selection}

Patients who had officially approved indication for LTx were registered on the waitlist provided by the Japan Organ Transplant Network (JOTN). Procedure indication was determined for each candidate according to the primary disease, urgency, and organ availability. Evidence of pathogenic airway resident bacteria or comorbid pulmonary hypertension was regarded as an indication for bilateral rather than single LTx. Offered deceased donor lungs were allocated to recipients according to waitlist order, $\mathrm{ABO}$ compatibility, and matching of predicted pulmonary vital capacity value. Detailed donor data including past medical history and results of examination were obtained by authorized donor coordinators. An experienced transplant physician delegated by the JOTN as a consultant for donor assessment and management were involved at an early stage of each process. The physician collected updated information on physical, radiologic, and bronchoscopic findings for each donor, and aided the staff at the local donor hospital in optimizing the donor's condition as much as possible. Surveillance respiratory sampling was performed via bronchoscopy to identify resident bacteria in the donor airway. Optimal antibiotic agents were chosen in accordance with sputum culture status and administered to the donor after confirming organ donation consent from the next of kin. The detailed donor data was shared among the donor hospital staff and transplant centers with the use of a form filled out by the authorized donor coordinators and transplant physicians. Our institutional expert team made a final decision to accept or decline the donor organs. Organ offers were not declined solely because of evidence of pathogenic bacteria in the donor's airway.

\section{Organ procurement and transplant procedure}

Lung procurement was standardized for all deceased donors. Donor lungs were routinely flushed with EP-TU extracellular solution (Cell Science \& Technology Institute, Sendai, Japan) with no antibiotics added to the flush solution. Ex vivo lung perfusion treatment was not performed in all the transplant cases of this study cohort. LTx surgery was performed in the standard manner via a transsternal anterior thoracotomy approach. Intraoperative cardiopulmonary support with a standard bypass technique was used when the unilateral native lung was not able to maintain adequate gas exchange and hemodynamic stability. When using cardiopulmonary bypass, intratracheal lavage through the tracheal tube was performed with tobramycin saline following bilateral pneumonectomy.

\section{Posttransplant management with antibiotics and immunosuppression}

Recipients received a standard triple-drug immunosuppressive regimen consisting of a calcineurin inhibitor (tacrolimus), a cell-cycle inhibitor (mycophenolate mofetil), and steroids. Target trough level of tacrolimus was set at $8-11 \mathrm{ng} / \mathrm{mL}$ for the first 30 days after LTx. A second-generation cephalosporin was routinely administered for the first 7 days posttransplant. When non-resident bacteria resistant to some antibiotics were 
detected in the donor or recipient preoperatively, broader spectrum antibacterial agents were selected in accordance with susceptibility testing and administered as a prophylaxis for $7-14$ days after surgery.

\section{Sputum sampling and definition of post-lung transplant pneumonia}

Sputum of both recipients and donors was sampled pretransplant. At the time of registration, the first sampling for recipients was performed. Then, at the time of LTx, recipient's sputum was reevaluated on the day before surgery. In addition, intrabronchial secretions of the recipients' explanted lungs and donor lungs were obtained through swabs intraoperatively and cultured. All the identified organisms were defined as the recipient/donor-derived bacteria. Thereafter, respiratory sampling for recipients was undertaken daily for the first 30 days after LTx. When a recipient was intubated, the sample was collected through bronchoscopy. Each sample was evaluated with gram staining and culture identification. Diagnostic criteria of PLTP included clinical, radiologic and culture factors. Recipients with productive airway secretion, fever and leukocytosis were further examined with a chest computed tomography scan to confirm convincing lung infiltration. We defined the development of PLTP as non-resident bacteria cultured more than twice in patients with clinical and radiologic evidence of pneumonia. Administration of antibiotics was tailored to the culture results and started immediately after the diagnosis of PLTP.

\section{Statistical analyses}

To determine the pre-transplant severity of each patient, their US lung allocation score (LAS) was retrospectively calculated (in November 2016) using the LAS calculator available on the OPTN website (https://optn.transplant.hrsa.gov/resou rces/allocation-calculators/las-calculator/). The primary graft dysfunction (PGD) grade was defined in accordance with the International Society for Heart and Lung Transplantation working group statement. The continuous and categorical variables were compared using the Mann-Whitney and Fisher's exact test, respectively. All donor-related variables that could conceivably predict PLTP development were tested using univariate regression analysis. A $p$-value $<0.05$ was considered to be statistically significant. The statistical analyses were performed using JMP ${ }^{\circledR} 11$ software (SAS Institute Inc., Cary, NC, USA).

\section{Results}

\section{Characteristics of the transplant cohort}

Thirty of 40 recipients underwent bilateral LTx and the remaining 10 underwent single LTx. The age of recipients ranged from 14-61 years (mean, 43 years), and 18 recipients $(45 \%)$ were female. Indications for LTx were interstitial lung disease $(n=13)$, idiopathic pulmonary arterial hypertension $(n=5)$, chronic obstructive pulmonary disease $(n=5)$, bronchiectasis $(n=5)$, and other miscellaneous pulmonary disorders $(n=12)$. There were no cystic fibrosis patients in this study cohort consisting entirely of Asian (Japanese) patients. As for the donors, ages ranged from 20 to 71 years (mean, 46 years), and there were 21 females (53\%). There were 24 donors with a smoking history of $>20$ pack-years. Four donors $(10 \%)$ died of trauma. Pathogenic bacterial isolates were positive pretransplant in 16 recipients and 23 donors.

\section{Development of PLTP and responsible bacterial organisms}

The breakdown of the cohort by PLTP development status is given in Fig. 1. Of the 40 LTx recipients, 17 developed PLTP (PLTP group) and the remaining 23 had no episode of pneumonia (non-PLTP group) throughout the first 30 days after LTx. In the PLTP group, time interval between LTx and PLTP onset ranged from 1-14 days (mean, 6 days). The responsible organisms in 13 of the 17 PLTP patients corresponded to the species detected in the recipients' pretransplant airway, while only three cases corresponded to donor-derived bacteria. In the remaining one case, the bacterial isolate (S. Maltophilia) conformed to neither the recipient's nor the donor's pretransplant airway resident species, implying that the PLTP was a de novo infection after LTx. Significantly higher incidence of PLTP was caused by recipient pretransplant airway bacteria than donor's. Overall, 13 (62\%) of 21 and $3(13 \%)$ of 24 cases showed an association between the bacteria responsible for PLTP and the recipient and donor pretransplant airway microflora, respectively $(p<0.01)$. As for 10 single LTx recipients, all of them had no bacterial colonization identified at the time of registration. However, three of them turned positive during the waiting time and had colonization when they underwent LTx. Eventually, there were one recipient-derived and one donor-derived PLTP in the single LTx cases. Both of the patients developed PLTP in the transplanted side. The bacterial species isolated pretransplant and at the onset of PLTP are given in Table 1. Staphylococcus and Pseudomonas were a common cause 


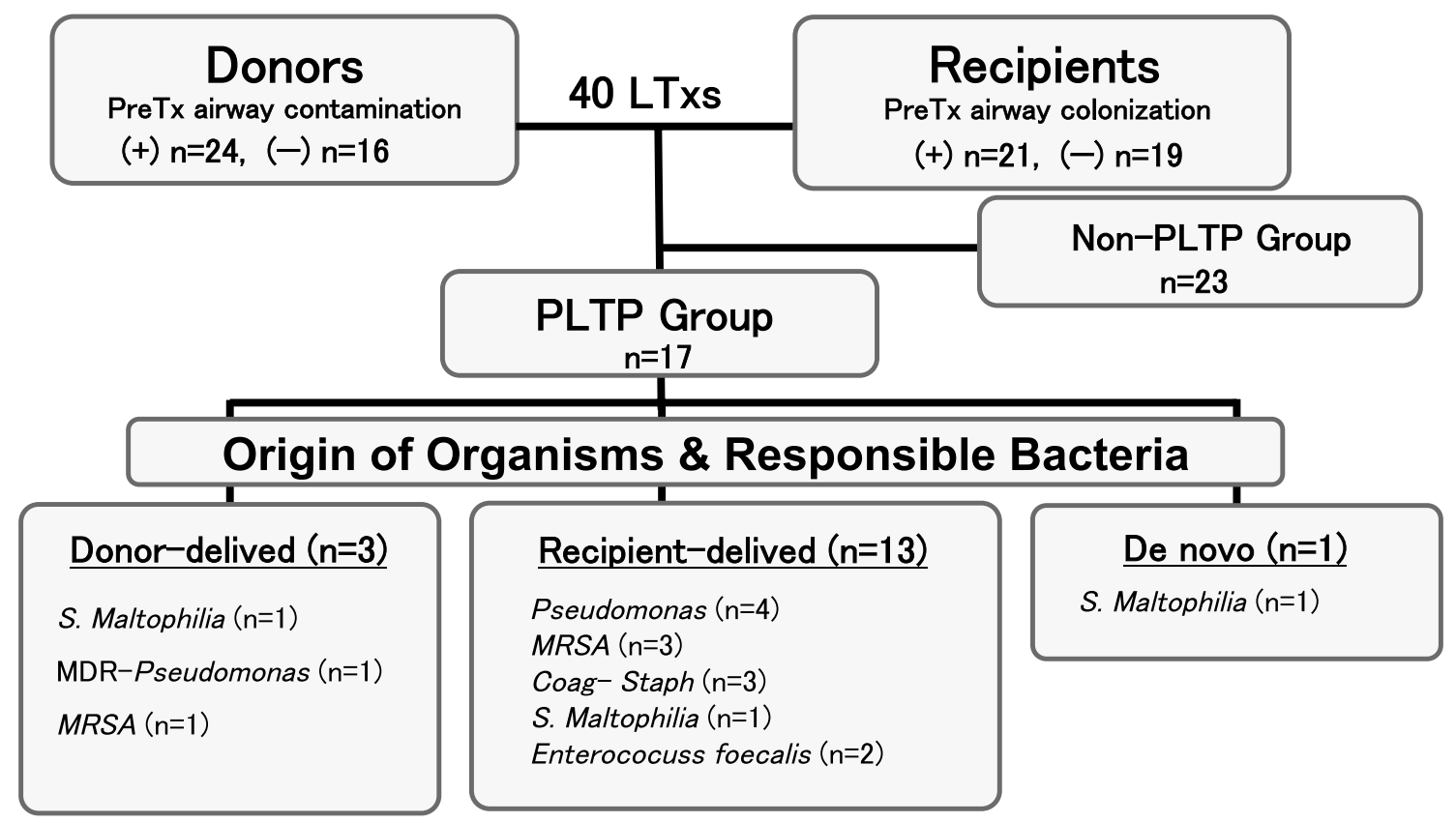

Fig. 1 Breakdown of the study cohort by clinical characteristics

Table 1 Organisms isolated from pretransplant and at PLTP onset

\begin{tabular}{llll}
\hline Microorganisms & \multicolumn{2}{l}{$\begin{array}{l}\text { No. of PLTP events/pre- } \\
\text { LTx identification }\end{array}$} \\
\cline { 2 - 3 } & Donors & Recipients & PLTP \\
\hline Gram-positive cocci & & & \\
MRSA & $1 / 4(25 \%)$ & $3 / 5(60 \%)$ & 4 \\
MSSA & $0 / 7$ & $0 / 2$ & 0 \\
Coag(-) staph & $0 / 0$ & $3 / 3(100 \%)$ & 3 \\
Enterococcus sp. & $0 / 0$ & $2 / 4(50 \%)$ & 2 \\
Gram-positive rods & & & \\
Corynebacterium sp. & $0 / 2$ & $0 / 0$ & 0 \\
Gram-negative rods & & & \\
Pseudomonas aeruginosa & $1 / 3(33 \%)$ & $4 / 12(33 \%)$ & 5 \\
S. maltophilia & $1 / 1(100 \%)$ & $1 / 1(100 \%)$ & 3 (de novo: 1$)$ \\
E. coli & $0 / 1$ & $0 / 1$ & 0 \\
Enterobacter cloacae & $0 / 9$ & $0 / 0$ & 0 \\
Klebsiella sp. & $0 / 3$ & $0 / 0$ & 0 \\
Acinetobacter baumanii & $0 / 2$ & $0 / 0$ & 0 \\
Serratia sp. & $0 / 2$ & $0 / 0$ & 0 \\
Mycobacterial & & & \\
Mycobacteriumu intracel- & $0 / 0$ & $0 / 1$ & 0 \\
$\quad$ lulare & & & \\
Fungi & & $0 / 3$ & 0 \\
Candida sp. & $0 / 3$ & $0 / 1$ & 0 \\
Aspergillus sp. & $0 / 0$ & & \\
\hline
\end{tabular}

MRSA methicillin-resistant Staphylococcus aureus, MSSA methicillin-susceptible Staphylococcus aureus, Coag(-) staph Coagulase-negative Staphylococcus of PLTP overall. Maltophilia was less frequently observed but caused high incidences of transmission events when identified pretransplant.

\section{Identification of PLTP risk factors}

Univariate and multivariate analyses comparing relevant clinical factors between PLTP and non-PLTP groups are shown in Table 2. Pretransplant positive airway culture in recipient $(p=0.01)$, donor smoking history $(p<0.01)$ and intraoperative cardiopulmonary bypass use $(p=0.03)$ were more frequently observed in the PLTP group. There was no statistical difference between the groups in other factors. Multivariate regression analysis including important clinical variables revealed that recipient's airway bacterial colonization $(p=0.02)$ and donor smoking status $(p=0.02)$ were the independent risk factors for PLTP development.

\section{Early and late posttransplant outcomes in the PLTP and non-PLTP groups}

For the overall study cohort, the mean PGD grade, length of mechanical ventilation and intensive care unit stay was $1.58,14.6$ days, and 25.1 days, respectively. When comparing between recipients with and without the PLTP development (PLTP and non-PLTP group), there was no statistical difference in the PGD grade. However, the length of mechanical ventilation (MV) requirement and intensive care unit (ICU) stay were significantly longer in the PLTP group (Fig. 2). The median posttransplant 
Table 2 Univariate and multivariate analyses for identification of PTP risk factor

\begin{tabular}{|c|c|c|c|c|}
\hline & $\begin{array}{l}\text { PLTP Group } \\
n=17\end{array}$ & $\begin{array}{l}\text { Non-PLTP Group } \\
n=23\end{array}$ & $\begin{array}{l}\text { Univariate } \\
p \text {-value }\end{array}$ & $\begin{array}{l}\text { Multivariate } \\
p \text {-value }\end{array}$ \\
\hline \multicolumn{5}{|l|}{ Recipient } \\
\hline Age (mean, range) & $48(14-61)$ & $40(21-57)$ & 0.79 & \\
\hline $\operatorname{Sex}(\mathrm{F} / \mathrm{M})$ & $8(47 \%) / 9(53 \%)$ & $10(43 \%) / 13(57 \%)$ & 1.00 & \\
\hline Primary disease (ILD/IPAH/COPD/BE/Other) & $\begin{array}{l}4(24 \%) / 3(18 \%) / 1 \\
\quad(6 \%) / 2(12 \%) / 7(41 \%)\end{array}$ & $\begin{array}{l}9(39 \%) / 2(9 \%) / 4 \\
\quad(17 \%) / 3(13 \%) / 5(22 \%)\end{array}$ & 0.56 & \\
\hline BMI (mean, range) & 19.5 & 18.7 & 0.35 & \\
\hline LAS & 35.0 & 33.7 & 0.14 & \\
\hline $\mathrm{DM}$ & $4(24 \%)$ & $5(22 \%)$ & 1.00 & \\
\hline preTx steroid usage & $7(41 \%)$ & $9(39 \%)$ & 1.00 & \\
\hline Positive airway culture & $13(76 \%)$ & $8(35 \%)$ & $\underline{0.01}$ & $\underline{0.02}$ \\
\hline \multicolumn{5}{|l|}{ Donor } \\
\hline Age (mean, range) & $9(39 \%)$ & $43(20-71)$ & 0.23 & \\
\hline $\operatorname{Sex}(\mathrm{F} / \mathrm{M})$ & $12(71 \%) / 5(29 \%)$ & $9(39 \%) / 14(61 \%)$ & 0.06 & \\
\hline BMI (mean, range) & $22.3(16.9-34.3)$ & $23.1(18.8-39.8)$ & 0.54 & \\
\hline Smoking at the time of brain death & $12(70.5 \%)$ & $4(17.4 \%)$ & $\underline{0.003}$ & $\underline{0.02}$ \\
\hline Cause of death (Trauma/non-Trauma) & $2(12 \%) / 15(88 \%)$ & $2(9 \%) / 21(91 \%)$ & 0.43 & \\
\hline Positive airway culture & $11(64 \%)$ & $13(57 \%)$ & 0.74 & 0.25 \\
\hline \multicolumn{5}{|l|}{ Operation } \\
\hline Type (Single/Bilateral) & $2(12 \%) / 15(88 \%)$ & $8(35 \%) / 15(65 \%)$ & 0.15 & 0.27 \\
\hline Blood loss (mL) & 1950 & 850 & 0.26 & \\
\hline CPB usage & $17(100 \%)$ & $15(65 \%)$ & $\underline{0.03}$ & 0.07 \\
\hline Graft ischemia time (min) & 551 & 526 & 0.40 & \\
\hline Max PGD grade (mean) & 1.9 & 1.4 & 0.43 & \\
\hline Prophylactic antibiotics (narrow/extended spectrum) & $7(41 \%) / 10(59 \%)$ & $11(49 \%) / 12(51 \%)$ & 1.00 & \\
\hline
\end{tabular}

$I L D$ interstitial lung disease, $I P A H$ idiopathic pulmonary arterial hypertension, $C O P D$ chronic obstructive pulmonary disease, $B E$ bronchiectasis, $B M I$ Body Mass Index, $L A S$ lung allocation score, $C P B$ cardiopulmonary bypass, $P G D$ primary graft dysfunction, $O R$ odds ratio, $95 \% C I 95 \%$ confidence interval
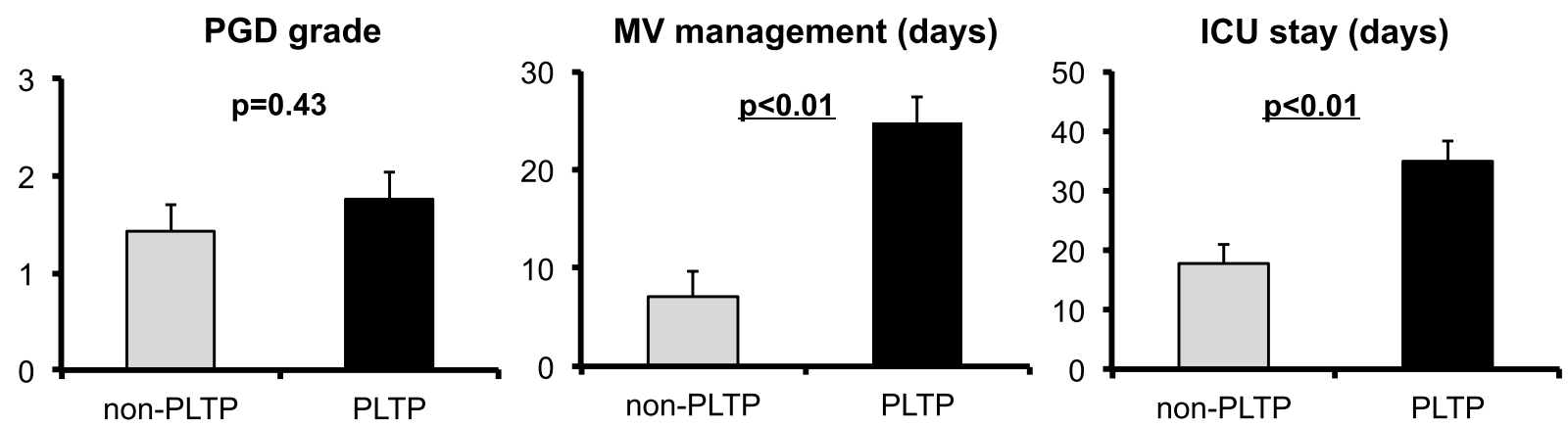

Fig. 2 Early posttransplant outcomes in the PLTP and non-PLTP group. PGD primary graft dysfunction, $M V$ mechanical ventilation, $I C U$ intensive care unit

follow-up time for the patient cohort was 6.4 years. Looking at the long-term outcomes, patients in the PLTP group exhibited significantly poorer survival than the non-PLTP group with higher incidence of chronic lung allograft dysfunction (CLAD) [13] despite no statistical betweengroup differences found regarding the incidence of CLAD (Fig. 3).

\section{Discussion}

Despite the recent improvement in the quality of perioperative management, infection still remains the leading cause of death during the first year after LTx $[10,11]$. The risk stratification regarding posttransplant graft infection 

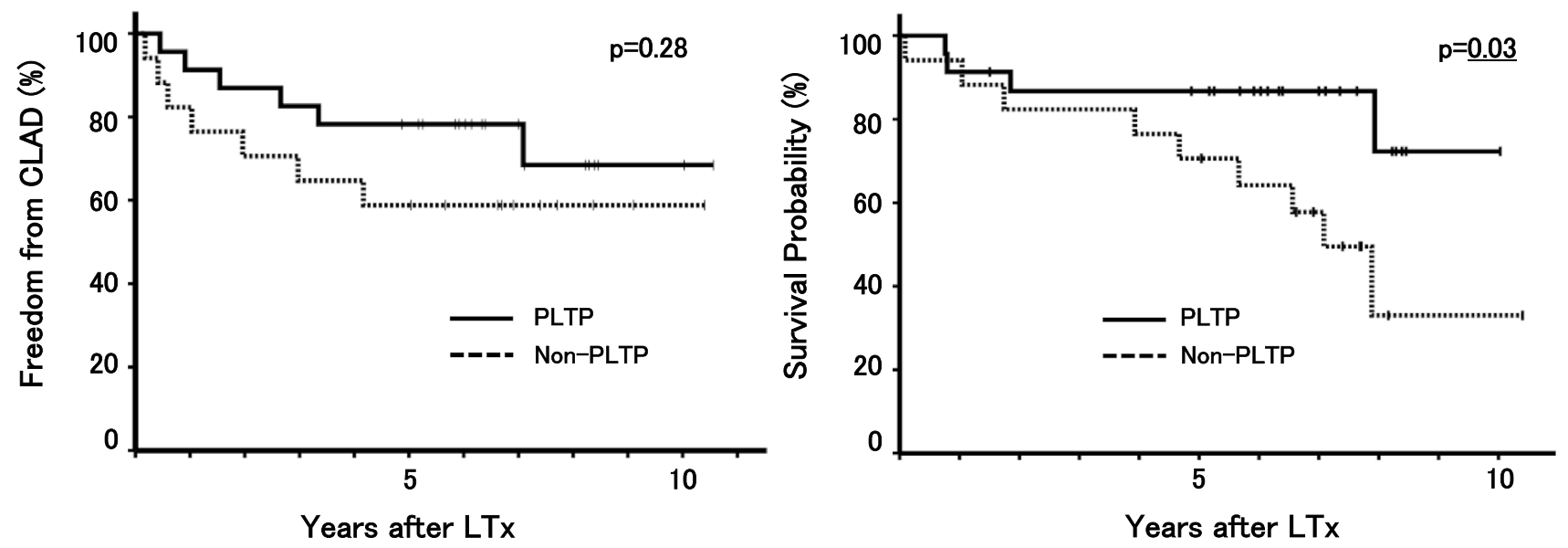

Fig. 3 Long-term outcomes in the PLTP and non-PLTP group. CLAD chronic allograft dysfunction, $L T x$ lung transplantation

is arguably one of the most important issues for donor selection and post-LTx patient management. However, it is hard to conduct a large-scale clinical study using a national-scale database and find conclusive evidence due to limitations of data collection such as a high rate of underreporting donor-transmission events [14]. In this study, we examined airway culture status for both donors and recipients preoperatively and exhaustively followed up with recipient sputum after LTx to explore the actual behavior of bacterial organisms in the donor's and recipient's original airway. Airway samples were obtained at least twice pretransplant in both donors and recipients, and daily for the first 30 days after LTx in the recipients. The close observation allowed for precise tracking of the cohort.

This study demonstrated that PLTP was mainly attributed to organisms originally from the recipient's rather than the donor's airway pretransplant. Indeed, the $62 \%$ of recipients with pretransplant airway infection or pathogenic-bacteria colonization developed PLTP thereafter, while a mere $13 \%$ of donors with positive culture testing results led to PLTP. In addition, donor smoking history was strongly associated with the development of PLTP. Lung transplant recipients with PLTP development spent longer under mechanical ventilation and ICU management posttransplant than those without. The early PLTP also affected the long-term outcomes. Overall, problematic graft infection early after LTx as well as long-term graft performance is strongly associated with donor's smoking history and the recipient's rather than the donor's airway contamination. According to the registry data in the International Society For Heart and Lung Transplantation, cystic fibrosis and other bronchiectasis accounted for $18 \%$ of global LTx indication [10]. A certain proportion of airway infectious diseases in LTx candidates can partly contribute to the relatively high incidence of infection early after LTx in the international database.
Furthermore, intraoperative $\mathrm{CPB}$ use seemed another risk factor for PLTP despite no reach to statistical significance in the multivariate regression analysis. This might be related to the fact that patients with intraoperative $\mathrm{CPB}$ requirement tend to be originally in more critical condition or need longer management of postoperative mechanical ventilation (data not shown).

A majority of past research indicated that there was no clear impact of donor airway infection on the early post-LTx outcome despite the fact that airway secretion status is cited as one of the standard donor acceptance criteria $[8,9,15,16]$. Reportedly, the positive rate of sputum Gram stains or culture tests in the offered lungs ranged from 50-89\%. In addition, $46-97 \%$ of transplanted lungs were from donors with positive pathogens [9, 15-17]. Airway contamination in lung donors is a common event, while the actual incidence of pneumonia after LTx from those donors was $<20 \%$ overall. Considering the data from the past and present study, a positive gram stain or bacterial culture by itself should not be a reason to preclude organ use. However, this view should be justified only if effective antibiotic prophylaxis is securely provided to donors and recipients. Some literature suggested that even organs procured from a donor with multidrug-resistant (MDR) pathogens could be successfully used under provision of prolonged tailored antibiotic treatment. However, other research has suggested that inappropriate management of MDR organisms led to high incidence of infectious transmission and critical events after LTx [18-20]. Indeed, our study cohort also included two of three donor-derived PLTPs that were caused by MDR pseudomonas and staphylococcus species and potentially not treated with effective antibiotics. Although adequate duration of prophylactic intervention remains debatable, some experts recommended at least 7-14 days of susceptibility-based antibiotic treatment against donor isolates [18, 20]. Overall, lungs from a donor with positive pathogens can be used but should 
be cautiously managed by conducting a sufficient length of on-target prophylaxis therapy.

Timely communication between donor hospital and transplant center is essential for clinicians to share the information for infection risk, optimal recipient selection, and prophylactic policy. The Organ Procurement and Transplantation Network in the US cautions against communication gaps that lead to higher incidence of transmission events [21]. We, in Japan, have a relatively small and close-knit community among transplant centers. The transplant consultant physicians from the closest centers are routinely invited to donor hospitals by the JOTN as a supervisor for donor management including sputum sampling through bronchoscopy and selection of antibiotics in each case. They acquire detailed important clinical data and share the information with other transplant centers. This unique system, which we call the "medical consultant system", has contributed to excellent quality control in donor information used in the recipient selection process, pre-procurement donor management, and communication between donor hospital staff and transplant centers. A high organ utilization rate has been achieved in our country, since this consulting regime was implemented [22]. Successful use of contaminated donor lungs in this study cohort was also attributed to those national efforts to enhance organ utilization.

There are several limitations inherent in the design of our study. First, it is retrospective in nature and investigated a small-scale patient cohort in a single center. Second, no fingerprinting analysis was conducted to confirm whether the collated bacterial isolates were genotypically identical or not. However, similarity in the bacterial phenotype and drug susceptibility between pre- and the very early post-transplant period is safely considered as the same pathogen. Finally, policy of antibiotics selection was not standardized. We eventually deferred to local attending physicians on antibiotic management.

In conclusion, donor smoking history and the recipient's original airway microflora rather than the donor's, are highly associated with PLTP. Therefore, a combination of donor smoking history and recipient's with airway infections should be avoided, while donor lung infection is not a contraindication for LTx.

Acknowledgements This research received no specific grant from any funding agency in the public, commercial, or not-for-profit sectors.

\section{Compliance with ethical standards}

Conflict of interest The authors declare no conflicts of interest.

\section{References}

1. Edwards L, Callahan R, Rogers J, Chan K. Predictors of deceased donor lung utilization in the United States. Abstract in American Transplant Congress. Am J Transplant. 2015;15:A66.

2. Loor G, Lyon C, Morrow J, Grabowski T, Kelly R, Hertz M, Morancy J, Patil J, Frankle D. Increasing lung utilization: implementation of a dedicated donor screening program. J Heart Lung Transplant. 2015;34:S280.

3. Smits JM, van der Bij W, Rahmel AO. Allocation of donor lungs. In: Fisher AJ, Verleden GM, Massard G, editors. European respiratory monograph: monograph 45-lung transplantation. Plymouth: European Respiratory Society Journals Ltd; 2009. p. 88-103.

4. Klein AS, Messersmith EE, Ratner LE, Kochik R, Baliga PK, Ojo AO. Organ donation and utilization in the United States, 1999-2008. Am J Transplant. 2010;10:973-86.

5. Reyes KG, Mason DP, Thuita L, Nowicki ER, Murthy SC, Pettersson GB, Blackstone EH. Guidelines for donor lung selection: time for revision? Ann Thorac Surg. 2010;89:1756-64.

6. Sirvent JM, Torres A, El-Ebiary M, Castro P, de Batlle J, Bonet A. Protective effect of intravenously administered cefuroxime against nosocomial pneumonia in patients with structural coma. Am J Respir Crit Care Med. 1997;155:1729-34.

7. Kalil AC, Metersky ML, Klompas M, Muscedere J, Sweeney DA, Palmer LB, Napolitano LM, O'Grady NP, Bartlett JG, Carratalà J, El Solh AA, Ewig S, Fey PD, File TM Jr, Restrepo MI, Roberts JA, Waterer GW, Cruse P, Knight SL, Brozek JL. Management of adults with hospital-acquired and ventilator-associated pneumonia: 2016 clinical practice guidelines by the infectious diseases society of America and the American Thoracic Society. Clin Infect Dis. 2016;63:e61-e111.

8. Weill D, Dey GC, Hicks RA, Young KR Jr, Zorn GL Jr, Kirklin JK, Early L, McGiffin DC. A positive donor gram stain does not predict outcome following lung transplantation. J Heart Lung Transplant. 2002;21:555-8.

9. Bonde PN, Patel ND, Borja MC, Allan SH, Barreiro CJ, Williams JA, Thakur NA, Orens JB, Conte JV. Impact of donor lung organisms on post-lung transplant pneumonia. J Heart Lung Transplant. 2006;25:99-105.

10. International Thoracic Organ Transplant (TTX) registry. Adult Lung Transplantation Statistics 2018. https://ishltregistries.org/ registries/slides.asp

11. Aguilar-Guisado M, Givaldá J, Ussetti P, Ramos A, Morales P, Blanes M, Bou G, de la Torre-Cisneros J, Román A, Borro JM, Lama R, Cisneros JM. Pneumonia after lung transplantation in the RESITRA Cohort: a multicenter prospective study. Am J Transplant. 2007;7:1989-96.

12. Valentine VG, Gupta MR, Walker JE Jr, Seoane L, Bonvillain RW, Lombard GA, Weill D, Dhillon GS. Effect of etiology and timing of respiratory tract infections on development of bronchiolitis obliterans syndrome. J Heart Lung Transplant. 2009;28:163-9.

13. Verleden GM, Glanville AR, Lease ED, Fisher AJ, Calabrese F, Corris PA, Ensor CR, Gottlieb J, Hachem RR, Lama V, Martinu T, Neil DAH, Singer LG, Snell G, Vos R. Chronic lung allograft dysfunction: Definition, diagnostic criteria, and approaches to treatment - a consensus report from the Pulmonary Council of the ISHLT. J Heart Lung Transplant. 2019;38:493-503.

14. Ison MG, Hager J, Blumberg E, Burdick J, Carney K, Cutler J, Dimaio JM, Hasz R, Kuehnert MJ, Ortiz-Rios E, Teperman L, Nalesnik M. Donor-derived disease transmission events in the United States: data reviewed by the OPTN/UNOS Disease Transmission Advisory Committee. Am J Transplant. 2009;9:1929-35.

15. Ruiz I, Gavaldà J, Monforte V, Len O, Román A, Bravo C, Ferrer A, Tenorio L, Román F, Maestre J, Molina I, Morell F, Pahissa 
A. Donor-to-host transmission of bacterial and fungal infections in lung transplantation. Am J Transplant. 2006;6:178-82.

16. Avlonitis VS, Krause A, Luzzi L, Powell H, Phillips JA, Corris PA, Gould FK, Dark JH. Bacterial colonization of the donor lower airways is a predictor of poor outcome in lung transplantation. Eur J Cardiothorac Surg. 2003;24:601-7.

17. Low DE, Kaiser LR, Haydock DA, Trulock E, Cooper JD. The donor lung: infectious and pathologic factors affecting outcome in lung transplantation. J Thorac Cardiovasc Surg. 1993;106:614-21.

18. Bishara J, Goldberg E, Lev S, Singer P, Ashkenazi T, Cohen J. The utilization of solid organs for transplantation in the setting of infection with multidrug-resistant organisms: an expert opinion. Clin Transplant. 2012;26:811-5.

19. Ariza-Heredia EJ, Patel R, Blumberg EA, Walker RC, Lewis R, Evans J, Sankar A, Willliams MD, Rogers J, Milano C, Razonable RR. Outcomes of transplantation using organs from a donor infected with Klebsiella pneumoniae carbapenemase (KPC)-producing K. pneumoniae. Transpl Infect Dis. 2012;14:229-36.

20. Mularoni A, Bertani A, Vizzini G, Gona F, Campanella M, Spada M, Gruttadauria S, Vitulo P, Conaldi P, Luca A, Gridelli B, Grossi
P. Outcome of transplantation using organs from donors infected or colonized with Carbapenem-resistant gram-negative bacteria. Am J Transplant. 2015;15:2674-82.

21. Miller R, Covington S, Taranto S, Carrico R, Ehsan A, Friedman B, Green M, Ison MG, Kaul D, Kubak B, Lebovitz DJ, Lyon GM, Nalesnik MA, Pruett TL, Teperman L, Vasudev B, Blumberg E. Communication gaps associated with donor-derived infections. Am J Transplant. 2015;15:259-64.

22. Hoshikawa Y, Okada Y, Ashikari J, Matsuda Y, Niikawa H, Noda M, Sado T, Watanabe T, Notsuda H, Chen F, Inoue M, Miyoshi K, Shiraishi T, Miyazaki T, Chida M, Fukushima N, Kondo T. Medical consultant system for improving lung transplantation opportunities and outcomes in Japan. Transplant Proc. 2015;47:746-50.

Publisher's Note Springer Nature remains neutral with regard to jurisdictional claims in published maps and institutional affiliations. 